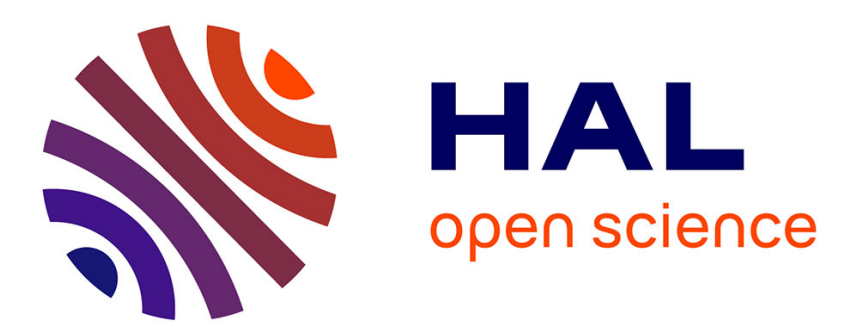

\title{
Further argument for the existence of a pacemaker in the human information processing system
}

\author{
Boris Burle, Michel Bonnet
}

\section{To cite this version:}

Boris Burle, Michel Bonnet. Further argument for the existence of a pacemaker in the human information processing system. Acta Psychologica, 1997, 97 (2), pp.129 - 143. 10.1016/S0001-6918(97)000280 . hal-01593517

\section{HAL Id: hal-01593517 https://hal.science/hal-01593517}

Submitted on 26 Sep 2017

HAL is a multi-disciplinary open access archive for the deposit and dissemination of scientific research documents, whether they are published or not. The documents may come from teaching and research institutions in France or abroad, or from public or private research centers.
L'archive ouverte pluridisciplinaire HAL, est destinée au dépôt et à la diffusion de documents scientifiques de niveau recherche, publiés ou non, émanant des établissements d'enseignement et de recherche français ou étrangers, des laboratoires publics ou privés. 
Acta Psychologica 97 (1997) 129-143

\title{
Further argument for the existence of a pacemaker in the human information processing system ${ }^{\text {仿 }}$
}

\author{
Boris Burle*, Michel Bonnet* \\ Centre de Recherche en Neurosciences Cognitives, Equipe Temps, Centre National de la Recherche Scientifique, 31 \\ chemin Joseph Aiguier 31, 13402, Marseille Cedex 20, France.
}

\begin{abstract}
To support the idea that temporal information processing may depend on an internal clock, Treisman et al. proposed a pacemaker model (Treisman, M., Faulkner, A., Naish, P.L.N., Brogan, D., 1990. The internal clock: Evidence for a temporal oscillator underlying time perception with some estimates of its characteristics frequency. Perception 19, 705-743.) and a technique for interfering with it by introducing an external periodic phenomenon. Experimental results obtained by these authors on time estimation and production tasks support this model. In another study, Treisman et al. established that the pacemaker also affects reaction times (RT) (Treisman, M., Faulkner, A., Naish, P.L.N., 1992. On the relation between time perception and the timing of motor action: Evidence for a temporal oscillator controlling the timing of movement. Quaterly Journal of Experimental Psychology 45A, 235-263.). In the present study, we addressed the question as to which information processing stage (Sanders, A.F., 1980. Stage analysis of reaction process, In: Stelmach, G.E., Requin, J. (Eds.). Tutorials in motor behavior. North-Holland, Amsterdam, pp. 331-354.) is affected by this internal clock. For this purpose, we used the Additive Factors Method (Sternberg, S., 1969. The discovery of processing stages: Extension of Donder's method. In: Koster, W.G. (Ed.). Attention and Performance II. Acta Psychologica 30, 276-315.). To vary sensorial processing time, we used two visual stimulus intensities. Stimulus response mapping was manipulated to enhance central processing time. To modify the duration of the motor stages, the two responses could be given by two fingers on the same hand (right ring vs. middle finger) or by two fingers of the different hands (right ring vs. left middle finger). Intensity of the stimulus, stimulus-response mapping, and repertoire of responses were found to be additive. We obtained RT modulations similar to those obtained by Treisman et al. in 1992 . No first order interactions were observed between the periodical phenomenon and the other manipulated factors but only a third order one. Two possible interpretations of these results are proposed.
\end{abstract}

\section{Introduction}

During the last few decades, a great number of work have addressed the question of the role of oscillations in information processing. Indeed, some experiments report periodicities

\footnotetext{
This is the author's (postprint) version of the article published in Acta Psychologica, 97 (1997) 129-143

*Present address of corresponding author: boris.burle@univ-amu.fr, Laboratoire de Neurosciences Cognitives, UMR7291, Aix-Marseille Université, CNRS, 3, place Victor Hugo, 13331 Marseille cedex 3

Postprint accepted in Acta Psychologica 97 (1997) 129-143

Accepted 17 May 1997
} 
in Reaction Time (RT) distributions (Dehaene, 1993; Harter and White,1968; Latour, 1967), and these periodicities have often been related to electrical cortical oscillations, mostly to $\alpha$ rhythm (Latour, 1967; Surwillo, 1963), or more recently to higher frequencies $(35-50 \mathrm{~Hz}$, i.e. $\beta$ band) (Lliás and Ribary, 1993; Treisman et al., 1994). These oscillatory phenomena have been proposed to serve as an internal clock (Treisman et al., 1994; Surwillo, 1963). Treisman et al. (1990, 1992, 1994), with a clever protocol, succeeded in systematically modifying subject's performance by interfering with the pacemaker of this "internal clock". Nevertheless, at present, the role of this internal clock in the various information processing stages (Sanders, 1980) is still unknown. Several hypotheses can be suggested. The first one was proposed by Stroud (1955) which he called "the perceptual moment hypothesis". According to this view, the sensory systems pack the continuous flow of information into perceptual episodes. This hypothesis has recently received a confirmation from psychophysical experiments (Purves et al., 1996; Andrews et al., 1996). This view is supported by the fact that cortical oscillations in the $\beta$ band (35-50 $\mathrm{Hz}$ ) seem to play an important role in sensory processing, at least in vision (Gray and Singer, 1989) and audition (Titinen et al., 1993). Nevertheless, many other experiments have pointed to the role of oscillatory phenomena in the motor system (Wing and Kristofferson, 1973a, b; Goodman and Kelso, 1983; Nashmi et al., 1994; Collyer et al., 1992, 1994), and some authors have proposed that the whole of information processing could be periodic and could depend on oscillatory mechanisms (Geissler, 1987; Harter, 1967; Latour, 1967; Surwillo, 1963).

But it is not clear if all these oscillations are related to a common pacemaker and if they have the same function at the various stages of information processing. The aim of the present work was thus to replicate Treisman and his collaborators important results, and to address these two questions. For this purpose we used their model of the internal clock and their experimental procedure coupled with the Additive Factors Method (Roberts and Sternberg, 1993; Sternberg, 1969).

Treisman's model consists of two parts: a temporal oscillator (TO) and a calibration unit (CU). The TO, modelled by Treisman in the form of a set of three neurons which interact together, emits pulses at a stable frequency, $F_{0}$. Its rhythm is transmitted to the $\mathrm{CU}$, which has a calibration coefficient, $C_{f}$. The pacemaker's output is the "corrected" frequency, $F p=C f F_{0}$. This mechanism yields a stable but easily adjustable frequency. If, for example, after the programming of a movement, an event occurs which makes it necessary to speed up execution, increasing the $C_{f}$ would produce the required effect without any loss of coordination, and there would be no need to re-program the movement all over again. Treisman hypothesized that even if the TO must be protected from outside stimulations to keep its frequency stable, a strong enough periodic sensory phenomenon might interfere with it. If the frequencies are similar, they will be set in phase, which will slow down the TO if the external frequency is lower than $F_{0}$ and speed it up in the opposite case. We thus obtain a characteristic interference pattern, Treisman showed that the value of $F_{0}$ can be estimated from this interference pattern (Treisman et al., 1990).

This model has been tested in duration estimation and production tasks while subjects were concomitantly exposed to clicks at different frequencies playing the role of "outside clock" (Treisman et al., 1990). In another experiment, Treisman and Brogan (1992) replicated their previous results using visual flicker instead of auditory clicks. The internal clock frequency values were estimated at 24.75, 37.3 and $49.5 \mathrm{~Hz}$, which square to 2, 3 and 4 times $12.4 \mathrm{~Hz}$. Then, addressing the question as to whether time estimation and motor control both involve the same mechanism, Treisman et al. (1992) extended these results to sensorimotor activities (choice RT and typing). In this case, the internal clock frequency was estimated to be $49.8 \mathrm{~Hz}$.

To explain the implication of the "internal clock" for RT, the following hypothesis can be 
made about the processing within a RT. Let us take a processing operation which lasts $x \mathrm{~s}$. This time corresponds to $n$ pacemaker cycles. If we slow down the pacemaker, the processing will still require the same number of cycles, but when these have a longer period, the duration of the processing will increase. If, on the contrary, we speed up the TO, the processing time will be shorter, but will still involve the same number of cycles. So if we vary the external stimulation frequency, we should therefore obtain the following: For values differing largely from $F_{0}$ (and from its harmonics), no effect, i.e. there is no drive on the internal clock; for values slightly lower than F0, an increase in the RT is due to the clock slowing down; for the value of $F_{0}$ (or $(m / n) F_{0}$ ), where $m$ and $n$ are integers with $\mathrm{m} \leqslant 5$ and $\mathrm{n} \leqslant$ (Treisman et al., 1990), no effect; and for values slightly higher than $F_{0}$, a decrease in the RT is due to the speeding up of the clock. What we expected to obtain when the external stimulation frequency increases step by step was therefore a pattern of "peak followed by dip" (Fig. I(A)).

One way of using the Additive Factors Method for the present purposes was as follows: While subjects are being subjected to periodic stimulations (liable to interfere with the internal clock), it is possible, by choosing appropriate factors, to increase the processing time at the sensory, central or motor stages ${ }^{1}$. It will then be possible to test the interactions between those factors and the periodic phenomenon,and hence to deduce the stage(s) at which this hypothetical internal clock intervenes. If the clock controls only one stage, any interference pattern will show up more clearly if this stage is lengthened. If, on the contrary, the clock influences all the stages, the interfering clicks will interact with all the factors manipulated. It is possible to vary the processing time of the identification stage by varying the stimulus intensity (weak vs. strong) (Nissen, 1977; Sternberg, 1969). The processing time of the central stage is known to be sensitive to the spatial compatibility of the stimulus and response (Fitts and Deiniger, 1954; Kornblum, 1992): in one case the onset of the right LED is associated with the right key (compatible situation), and in the opposite case, the onset of the right LED required pressing of the left key (incompatible situation). The processing time is always greater in the last situation. A further set of responses involving unimanual vs. bimanual conditions can be used to elicit changes in the motor stages processing time (motor programming and execution) (Hasbroucq and Possamai, 1995; Hasbroucq et al., 1995; Kornblum, 1965). In the first condition, the fingers used are the right ring finger and middle finger, and in the second condition, the right ring finger and left middle fingers, so that the right ring finger was always associated with the response key farthest on the right. These three factors have been used in previous studies, and their effects are known to be additive (Azorin et al., 1995; Hasbroucq et al., 1989; Schulman and McConkie, 1973).

The interaction between the periodic sensory stimulation and the other factors we expected to occur is as follows: If the duration of a stage is prolonged by a factor, i.e. its processing takes longer, this will mean that the number of cycles has increased. In this case a phase setting will occur more frequently, any interference pattern will show up more clearly, and its amplitude will be greater (Fig. I(A)). If on the contrary no interaction occurs, there will be no changes in the amplitude of the interference pattern.

\footnotetext{
${ }^{1}$ In this study, we used the minimal decomposition of $\mathrm{R} T$ in three stages proposed by Proctor et al. (1990): stimulus identification, stimulus-response translation, and response programming.
} 

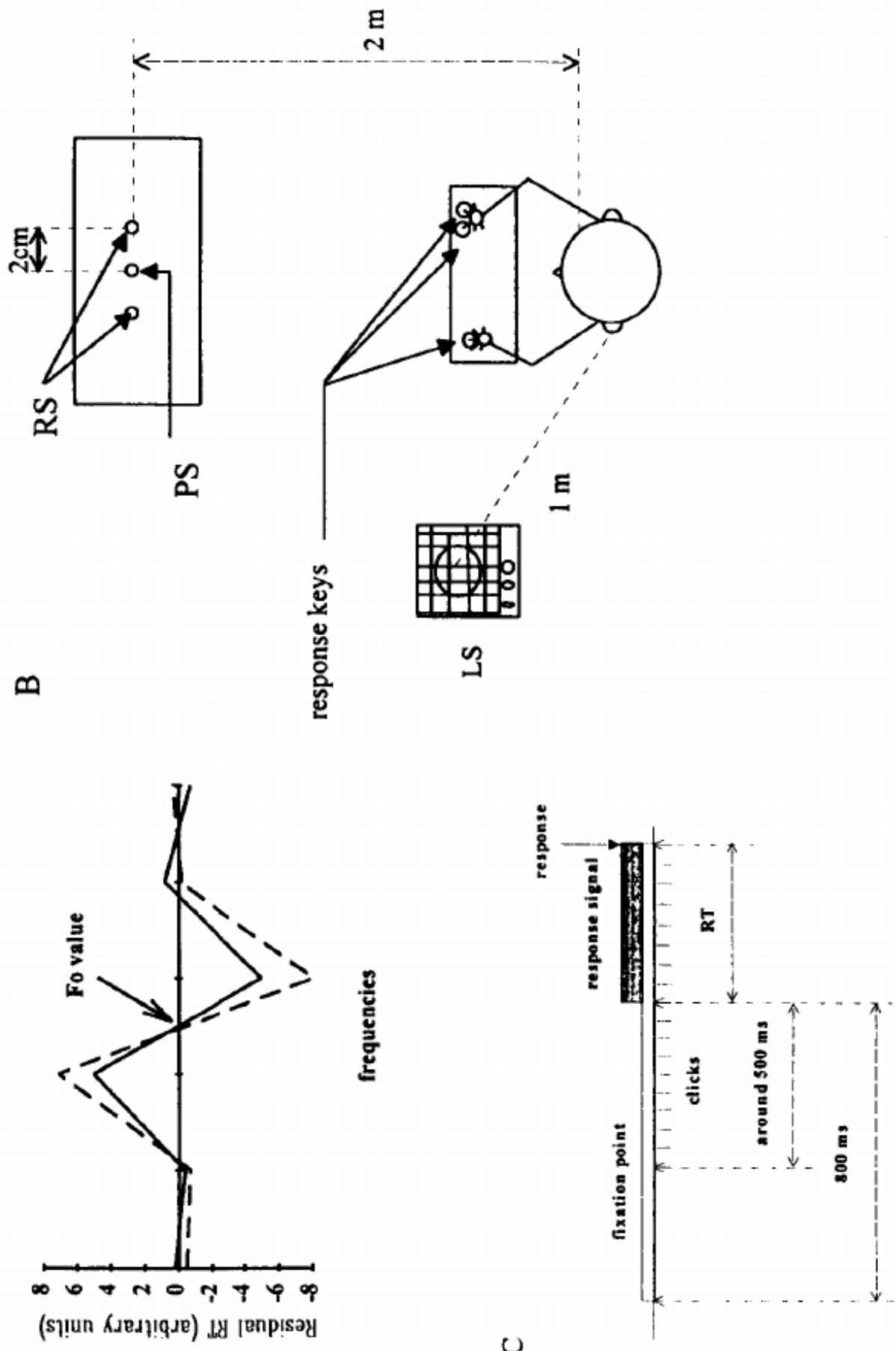

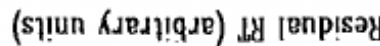

Figure 1: (A) Representation of the interference pattern. The dotted line shows the expected interaction between the clicks frequency and the factors influencing the various stages. (B) diagram of the experimental apparatus. The subject is seated at about $2 \mathrm{~m}$ from the RS display. The loudspeaker (LS) is at about $1 \mathrm{~m}$ from the subject head. (C) diagram of one trial: the fixation point switches on $800 \mathrm{~ms}$ before the RS and the clicks stopped with the subject's response. 


\section{Method}

\subsection{Subjects}

Eight male subjects, aged from 22 to 39 years (mean: 26 years), participated in the experiment. Seven of the subjects were right handed, and one was left handed. They gave informed consent and were paid for participating.

\subsection{Apparatus and task}

The subject was comfortably seated, $2 \mathrm{~m}$ away from three horizontal LEDS about $2 \mathrm{~cm}$ apart, placed at eye level (Fig. I(B)). The central LED, which was blue, was used as a fixation point, and the two lateral ones, which were green, were used as response signals (RSs). The two stimulus intensities we used were set at 0.6 and 4.5 mcd for weak and strong, respectively. The subject's hands were placed with the fingers slightly apart on a set of three response keys (Fig. $\mathrm{I}(\mathrm{B}))$. At the onset of the RS, the subject had to press the key corresponding to the stimulus as fast as possible. As previously described, we used stimulus intensity, stimulus/response spatial compatibility, and two repertoires of responses to enhance the processing time of the various stages. The external periodic stimulation consisted of trains of auditory clicks delivered by a loudspeaker placed about $1 \mathrm{~m}$ from the subject. On the basis of Treisman's results, 11 frequencies were used, from 19.4 to $25.4 \mathrm{~Hz}$, in $0.6 \mathrm{~Hz}$ steps. The order of the frequencies within each block was varied randomly. The click's intensity was about $71 \mathrm{~dB}(\mathrm{~A})$. All the factors were crossed. The experiment consisted of four blocks of 440 trials each. Since the response stimulus intensity and the external frequency were manipulated within each block, four blocks were required: block 1 , compatible unimanual; block 2, compatible bimanual; block 3, incompatible unimanual; block 4 , incompatible bimanual. The order of blocks was balanced between subjects. At the initial training sessions, the subjects underwent four training blocks, without any clicks, consisting of 60 trials each. Each of four subsequent sessions consisted of one experimental block with clicks included. Repertoire and compatibility were fixed in a session, and four conditions varied (intensity crossed with response side). Subjects underwent 10 trials with each frequency, so that each experimental block consisted of $10 \times 11 \times 4=440$ trials. Since trials in which incorrect responses occurred, i.e. key errors, double presses or no response within the time limit of 800 ms, were re-run, we obtained $4 \times 440=1760$ correct trials/subject. In each trial, the fixation point was switched on $800 \mathrm{~ms}$ before the RS. To prevent the RS onset between two clicks from affecting the frequency of the sensory stimulation, it was always synchronized with a click (Fig. $\mathrm{I}(\mathrm{C})$ ), so the clicks were delivered about $500 \mathrm{~ms}$ before the RS. Since the onset of the RS was always synchronized with a click, the time between the beginning of the click train and the RS was frequency-dependent. This yielded variations ranging between 500 and $537 \mathrm{~ms}$ (see Section 4.4). Pressing a key stopped the click train. If the response was incorrect, an error message was delivered: ANTICIPATION = key pressing before the RS, TOO LATE $=$ response after $800 \mathrm{~ms}$, ERROR = wrong key or double press. The duration between two onsets of the fixation point was set at $6 \mathrm{~s}$. The effective duration of a block was therefore $(6 \times 440) / 60=44 \mathrm{~min}$. Rest breaks were introduced after the $110^{\text {th }}, 220^{\text {th }}$ and $330^{\text {th }}$ trials and subjects could ask for a rest whenever they wished. The actual duration of each block was therefore roughly $1 \mathrm{~h}$, and subjects underwent only one block per session.

\section{Data processing}

As the first goal of this experiment was to replicate the results of Treisman and collaborators, data processing was similar to that performed by these authors. According to Treisman's model, 


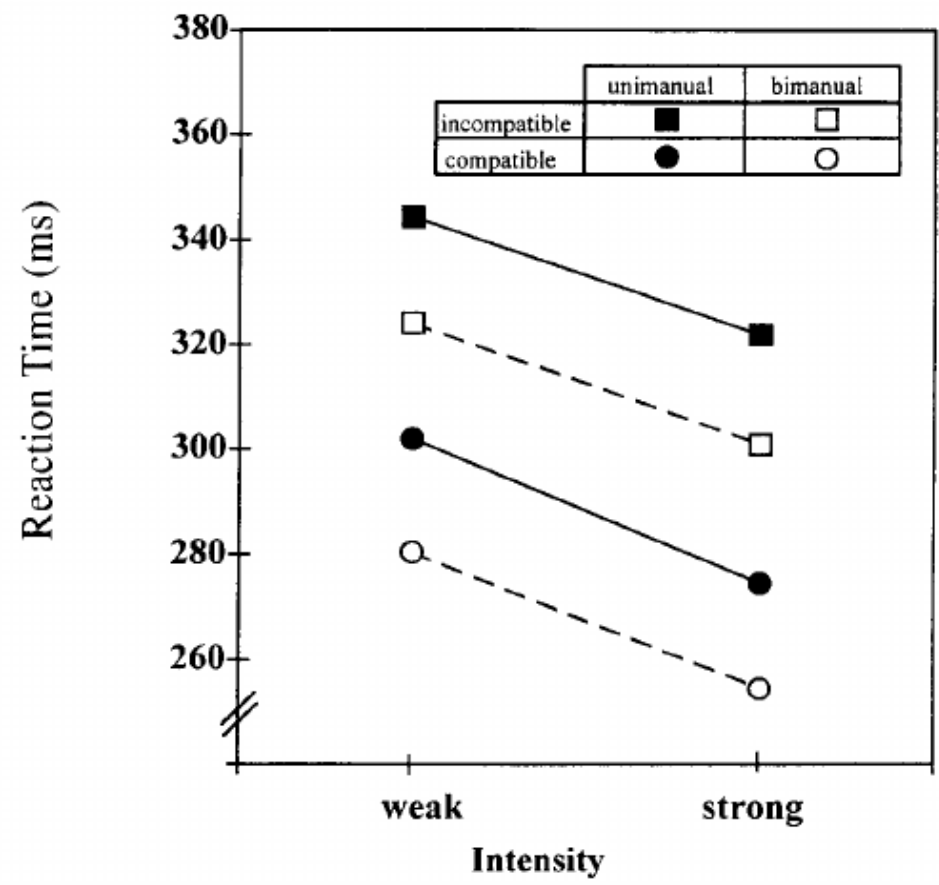

Figure 2: Average RT for the eight subjects for each condition as a function of the intensity of the stimulus.

the click frequencies were assumed to have an approximately linear nonspecific activatory effect on the CU. This effect has been recently demonstrated by Penton-Voak et al. (1996). To distinguish it from the nonlinear interference effect we are interested in, a regression analysis was carried out following Treisman's method.

For each subject and for each of the eight elementary experimental conditions (weak intensitycompatible-unimanual, strong intensity-compatible-unimanual, weak intensity-incompatible- unimanual, strong intensity-incompatible-unimanual etc...) we calculated the median RT for each frequency. We thus obtained one median per frequency $f$ in each condition. Within each condition, we calculated separately the linear regression: $R T=a \times f+b$ with the 11 medians corresponding to the 11 frequencies. We therefore calculated 11 residual RT per condition (residual RT = recorded RT - estimated RT). We then averaged all those residuals for each frequency across the eight conditions for each subject. We therefore ended up with a distribution of 11 mean residuals per subject on which the search for interference patterns, a peak followed by a dip, was carried out. If these patterns were due to the interference of the external frequency with the internal clock, their position in the frequency range was likely to be relatively constant. If this was not the case, their distribution was bound to be random. The search for interference patterns was carried out as follows: whenever a peak, i.e. a positive residual higher than its two neighbours, immediately followed by a dip, i.e a negative residual lower than its two neighbours (or only with a point close to zero between them, i.e. the pattern could never exceed three frequencies) was detected, we noted its position on the interval where the curve crosses 0 (this was presumably the position of $F_{0}$ ) (10 possible intervals). By this procedure we can look at the number of subjects 
presenting a pattern for each interval of frequency. The random vs. systematic character of the click effect was tested using a chisquare test with nine degrees of freedom (10 intervals - 1).
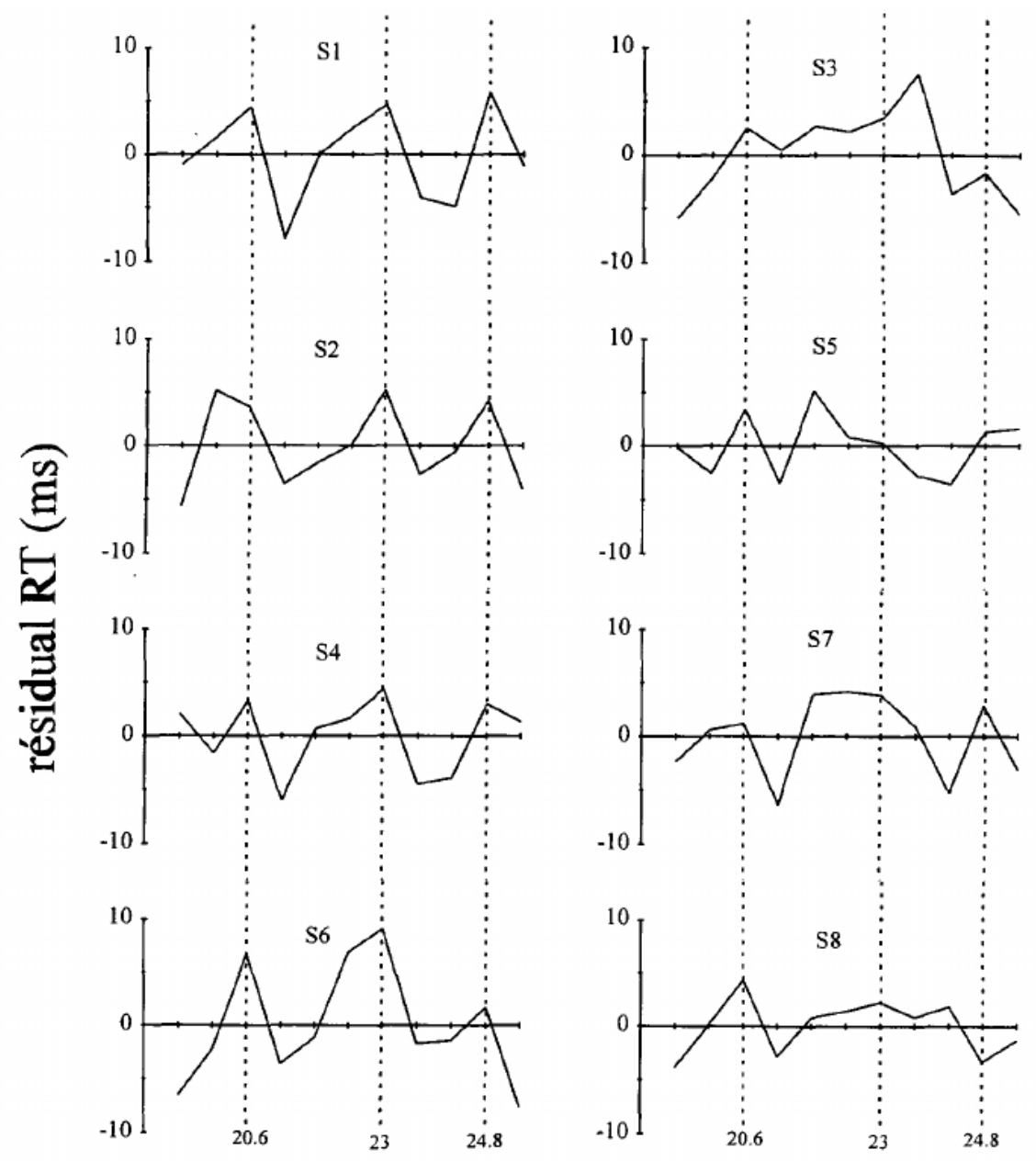

Clicks frequencies $(\mathrm{Hz})$

Figure 3: Distribution of the residuals obtained for the eight subjects as a function of the eleven clicks frequencies.

\section{Results}

The error rate in the whole experiment was $1.99 \%$. An ANOVA was performed on the arcsinus of the error rate. Only intensity had an effect on error rate, more errors were made with weak intensity $(F(1,7)=5.709 ; p<0.05)$. 


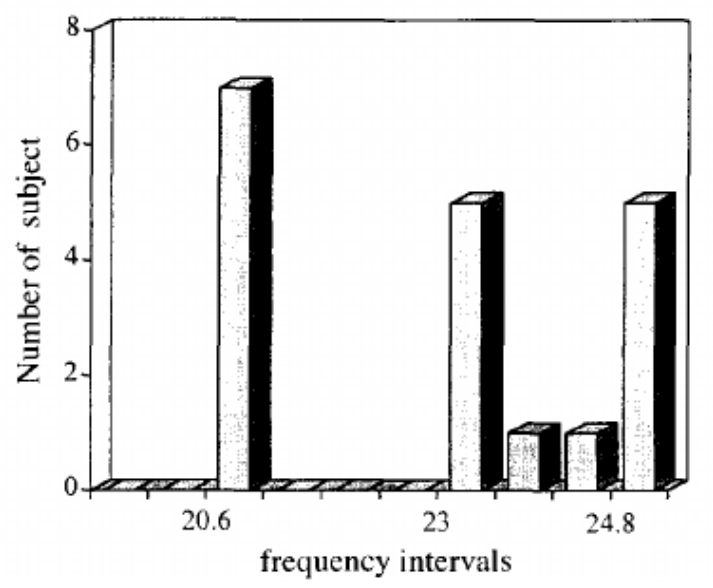

Figure 4: Histogram of the number of subjects presenting an interference pattern as a function of frequency intervals.

\subsection{Average $R T$}

The analysis was carried out on mean values, because medians are not suitable for testing additivity (Sternberg, 1969), and only on right ring finger data to avoid any effect of response fingers. The subjects were faster when the stimulus/response mapping was compatible (278 ms) than when it was incompatible $(323 \mathrm{~ms})(F(1,7)=24.938 ; p<0.01)$. The bimanual responses were shorter $(290 \mathrm{~ms})$ than unimanual ones $(311 \mathrm{~ms})(F(1,7)=11.796 ; p<0.025)$. When the intensity was strong, the RT was shorter $(288 \mathrm{~ms})$ than when it was weak $(313 \mathrm{~ms})(F(1,7)=$ 403.386; $p<<0.001)$. The effects of these three factors were additive. The values of $F$ for the different interactions are: $F(1,7)=3.5$ for intensity $\times$ compatibility, $F(1,7)=0.19$ for intensity $\times$ repertoire, $F(1,7)=0$ for repertoire $\times$ compatibility and $F(1,7)=0.209$ for the three way interaction (intensity $\times$ compatibility $\times$ repertoire). All the critical probabilities are above 0.10 (Fig. 2).

\subsection{Effects of clicks and search for patterns}

Fig. 3 shows the residual RTs for the eight subjects, and Fig. 4 shows the number of subjects presenting a pattern for each frequency interval. Seven subjects out of the eight showed a pattern at $20.9 \mathrm{~Hz}$, five out of the eight showed two patterns at 23.3 and $25.1 \mathrm{~Hz}$, and only two subjects showed a pattern at other frequencies. This distribution was significantly different from random $\left(\chi_{9}^{2}=34,16 ; p<0.001\right)$.

\subsection{Interactions between clicks and the other factors}

To test only the nonlinear effects on the RT, an analysis of variance was carried out on residual RTs following a full $11 \times 2 \times 2 \times 2$ design. The residual means for each of the eight conditions were always equal to zero. With this analysis it was therefore not possible to test the effects of intensity, compatibility, and repertoire. It served however to show whether there existed any effects of the click frequencies, and whether any interactions occurred between the clicks and the other factors. We used in this analysis the $N-2$ degrees of freedom of the regression analysis for the "frequencies" factor, i.e. $11-2=9$. Click frequency was found to have had a significant main effect $(F(9,63)=2.417 ; p<0.025)$. The analysis showed that there existed only a slight tendency 


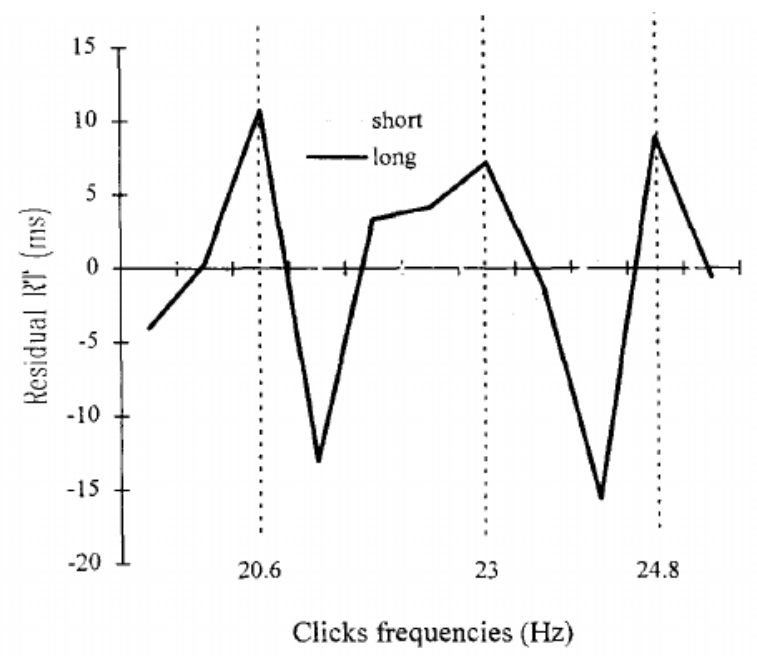

Figure 5: Mean residuals obtained for the shortest mean RT and longest mean RT as a function of the frequencies.

Table 1: Auditory FP duration as a function of stimulation frequencies

\begin{tabular}{|c|c|c|c|c|c|c|c|c|c|c|c|}
\hline Frequencies $(\mathrm{Hz})$ & 19.4 & 20 & 20.6 & 21.2 & 21.8 & 22.4 & 23 & 23.6 & 24.2 & 24.8 & 25.4 \\
\hline FP duration (ms) & 515 & 500 & 534 & 519 & 505 & 536 & 522 & 508 & 537 & 524 & 512 \\
\hline
\end{tabular}

toward an interaction between frequency and intensity, but these were far from reaching the conventional significance level of $0.05(F(9,63)=1.788 ; p=0.10)$. The analysis did not reveal any interaction between frequency and compatibility, neither with repertoire $(F(9,63)=1.52$ and $F(9,63)=0.77$ for compatibility and repertoire respectively). This suggests that the clock does not operate on the various stages of information processing which were sensitive to the factors we used nor were any of the three way interactions involving click frequency significant $(F(9,63)=1.01$ for frequency $\times$ intensity $\times$ compatibility; $F(9,63)=0.23$ for frequency $\times$ intensity $\times$ repertoire and $F(9,63)=1.27$ for frequency $\times$ compatibility $\times$ repertoire). Nevertheless the fourth way interaction was found to be significant $(F(9,63)=2.48 ; p<0.025)$. It is possible that this may have been due to an interaction between frequencies and RT duration. Fig. 5 shows the mean values of residuals for the eight subjects for the longest mean RT (weak intensity/incompatible/unimanual situation) and the shortest mean RT (strong intensity/compatible/bimanual situation). The amplitude is bigger for "long" RTs than for "short" ones.

\subsection{Possible effects of the variations of the auditory "foreperiod"}

The drastic onset of the click train could serve as a supplementary preparatory signal (PS). As the RS was always synchronized with a click (see Section 2), the time of this onset according to the RS is not constant across the frequencies. As the variations of the foreperiod (FP) from 500 to $537 \mathrm{~ms}$ (Table 1) resemble the modulations of the RT, a possible role of these variations needs to be investigated. Indeed, it is well known that the FP duration affects RT, especially the motor components (Hasbroucq et al., 1995; Sanders, 1990). Nevertheless, the differences in the FP used in the literature are far more important than the variations here, and it seems to be very 
Table 2: Correlation coefficients for the eight subjects: mean $-0.16+0.25$ (calculated on $\mathrm{z}$ transform). The weakest value to reach 0.05 significance level with nine degrees of freedom (11 frequencies - 2) is 0.60 , and 0.52 for 0.10 level. Only one subject (S6) shows a significant correlation between the two variables

\begin{tabular}{lc}
\hline Subjects & $r$ \\
\hline S1 & 0.42 \\
S2 & 0.14 \\
S3 & -0.04 \\
S4 & -0.06 \\
S5 & -0.24 \\
S6 & $0.62^{*}$ \\
S7 & -0.01 \\
S8 & 0.34 \\
\hline
\end{tabular}

unlikely that such few variations could modify the RT in this way. For example, between 20.6 and $21.2 \mathrm{~Hz}$, the difference in FP is $15 \mathrm{~ms}$, and the difference in RT is $8 \mathrm{~ms}$. This corresponds approximately to the effects obtained by Drazin (1961) when the FP varied from 500 to $1000 \mathrm{~ms}$. Nevertheless, if an effect of the FP duration does exist, we should predict a correlation between the duration of the FP and the RT. In order to test this possibility, we analysed the RT according to the FP duration and we computed for each subject the correlation coefficient between RT and FP duration (Table 2). Only one subject (\#6) shows a significant correlation between the two variables and the average correlation calculated on $z$ transform is 0.16 . According to these results, the effect of FP duration, if it exists, seems to be unlikely to explain the greatest part of the RT modulations we observed as a function of the frequencies.

\section{Discussion}

The first goal of this experiment was to replicate the results of Treisman et al. (1992). The systematic distribution of interference patterns observed in this study confirms Treisman's data and supports his model by suggesting that there exists a pacemaker which affects the RT. The second goal of this experiment was to determine the stages at which such a pacemaker intervenes in the information processing system. The lack of first order interactions is rather problematic, and tends to suggest that the clicks may have affected something other than the stages we tested. One possibility is that the pacemaker may involve processing stages which are not influenced by the factors "intensity", "compatibility" and "repertoire". However, according to Sander's review (Sanders, 1980) the sensorial, central and motor stages seem to have been involved in the effects of our manipulations. Another possibility is that some interactions may have occurred but that the factor manipulation did not reveal them because the effect sizes were quantitatively low, $25 \mathrm{~ms}$ for intensity, $45 \mathrm{~ms}$ for compatibility and $21 \mathrm{~ms}$ for repertoire, while for the external stimulation its drive effect seems to be about $2 \%$ of the whole RT. The estimation of the drive value was performed by computing the percentage of the RT which corresponds to the mean value of the pattern amplitudes obtained from Fig. 5 for "short" $(1.6 \%)$ and "long" $(2.7 \%)$ RT. The expected interaction between, for example, clicks and compatibility is $2 \% \times 45 \mathrm{~ms}=0.9$ ms. In this case, we shall have to use factors which influence more the stages processing time. The third possible explanation for these results is that the lack of interactions may be real, and that the pacemaker may not intervene during these information processing stages, but may act on the transmission from one stage to the other (Miller, 1988). Suppose that transmission between 
stages is subjected to a "gating system" opening in a discrete way, such that the products of one stage can only be conveyed to another at definite moments corresponding to the opening of the "gate". If the external periodic phenomenon interferes with this gating system, one can expect a modulation of the RT to occur but not an interaction with the factors which influence the stage duration. It still remains however to account for the third order interaction and for the interaction with RT duration. During the performance of choice RT tasks, some studies have reported that on some trials some muscular activity occurred on the side contralateral to the expected response, but was not sufficiently strong to produce a response (Eriksen et al., 1985). After a delay, a more sizeable muscular activity occurred triggering the correct response. The time elapsing between incorrect and correct activities is called the correction time. The correction time is sensitive to manipulated factors (Eriksen et al., 1985): For example, the correction time was found to be longer in an incompatible spatial S-R situation than in a compatible situation. This suggests that subjects went back through some processing stages before giving the correct response, causing more inter stage transmissions to take place. Now more such incorrect/correct trials are known to occur in "complex" tasks than in "simple" tasks (Smid et al., 1990), which means that the probability of obtaining an increase in the number of transmissions is greater in "complex" tasks (long RTs) than in simpler tasks (short RTs). This suggests that any interaction with the RT duration and/or the difficulty of the task may in fact be due to an interaction with presence vs. lack of incorrect/correct trials. So, models of two kinds seem to be able to explain the data obtained up to now. On the one hand, the clock could either control the transformation of the information within stages, or affect the transmission of the information between stages. Experiments for testing these hypotheses are in progress.

\section{Acknowledgements}

We thank M. Treisman for his helpful comments on an earlier draft of the manuscript. We are grateful to M. Chiambretto for having developed the computer program and to T. Hasbroucq, A. Osman and two anonymous reviewers for their helpful suggestions. This research was supported in part by a research grant D.R.E.T. no. 94-131.

\section{References}

Andrews, T.J., White, L.E., Binder, D., Purves, D., 1996. Temporal events in cyclopean vision. Proceedings of the National Academy of Science USA 93, 3689-3692.

Azorin, J.M., Benhaïm, P., Hasbroucq, T., Possamaï C.A., 1995. Sensory and central processing in depression: A reaction time study. Acta Psychologica 89, 95-100.

Collyer, C.E., Broadbent, H.A., Church, R.M., 1992. Categorical time production: Evidence for discrete timing in motor control. Perception and Psychophysics 51 (2), 134-144.

Collyer, C.E., Broadbent, H.A., Church, R.M., 1994. Preferred rates of repetitive tapping and categorical time production. Perception and Psychophysics 55 (4), 443-453. Dehaene, S., 1993. Temporal oscillations in human perception. Psychological Science 4 (4), 264-270.

Drazin, D.H., 1961. Effects of foreperiod, foreperiod variability, and probability of stimulus occurrence on simple reaction time. Journal of Experimental Psychology 62, 43-50.

Eriksen, C.W., Coles, M.G.H, Morris, L.R., O’Hara, W.P., 1985. An electromyographic examination of response competition. Bulletin of the Psychonomic Society 23, 165-168.

Fitts, P.M., Deiniger, R.L., 1954. S-R compatibility: Correspondence among paired elements within stimulus and response code. Journal of Experimental Psychology 48, 483-492. 
Geissler, H.G., 1987. The temporal architecture of central information processing: Evidence for a tentative time-quantum model. Psychological Research 49, 99-106.

Goodman, D., Kelso, J.A.S., 1983. Exploring the functional significance of physiological tremor: A biospectroscopic approach. Experimental Brain Research 49, 419-431.

Gray, C.M., Singer, W., 1989. Stimulus specifics neuronal oscillation in orientation columns of cat visual cortex. Proceedings of the National Academy of Science USA 86, 1698-1702.

Harter, M., 1967. Excitability cycles and cortical scanning: A review of two hypotheses of central intermittency in perception. Psychological Bulletin 68 (1), 47-58.

Harter, M., White, C.T., 1968. Periodicity within reaction time distributions and electromyograms. The Quaterly Journal of Experimental Psychology 20 (2), 157-166.

Hasbroucq, T., Akamatsu, M., Mouret, I., Seal, J., 1995. Fingers pairings in two choice reaction time tasks: Does the between hands advantage reflect response preparation? Journal of Motor Behavior 27, 251-262.

Hasbroucq, T., Guiard, Y., Kornblum, S., 1989. The additivity of stimulus-response compatibility with the effects of sensory and motor factors in a tactile choice reaction time task. Acta Psychologica 72, 139-144.

Hasbroucq, T., Possamai, C.A., 1995. Does irrelevant stimulus location affects response selection? Canadian Journal of Experimental Psychology 49, 349-356.

Kornblum, S., 1965. Response competition and/or inhibition in two-choice reaction time. Psychonomic Science 2, 55-56.

Kornblum, S. 1992. Dimensional overlap and dimensional relevance in stimulus-response and stimulusstimulus compatibility. In: Stelmach, G.E., Requin, J., (Eds.), Tutorials in Motor Behavior, Elsevier, Amsterdam, pp. 743-777.

Latour, P.L., 1967. Evidence of internal clocks in the human operator. Acta Psychologica 27, 341-348.

Llinás, R., Ribary, U., 1993. Coherent $40 \mathrm{~Hz}$ oscillation characterizes dream state in humans. Proceedings of the National Academy of Science USA 90, 2078-2081.

Miller, J., 1988. Discrete and continous models of human information processing: Theoretical distinctions and empirical results. Acta Psychologica 67, 191-257.

Nashmi, R., Mendoga, A.J., MacKay, W.A., 1994. EEG rhythms of the sensorimotor region during hand movements. Electroencephalography and clinical Neurophysiology 91, 456467.

Nissen, M.J., 1977. Stimulus intensity and information processing. Perception and Psychophysics 22, 338-352.

Penton-Voak, I.S., Edwards, H., Percival, A., Wearden, J.H., 1996. Speeding up an internal clock in humans? Effects of click trains on subjective duration. Journal of Experimental Psychology: Animal Behavior Processes 22 (3), 307-320.

Proctor, R.W., Reeve, T.G., Weeks, D.J., 1990. A triphasic approach to the acquisition of responseselection skill. In: Bower, G.H. (Ed.), The Psychology of Learning and Motivation. Academic Press, New York, pp. 207-240.

Purves, D., Paydarfar, J.A., Andrews, T.J., 1996. The wagon wheel illusion in movies and reality. Proceedings of the National Academy of Science USA 93, 3693-3697.

Roberts, S., Sternberg, S., 1993. The meaning of additive reaction time effects: Tests of three alternatives. In: Meyer, D.E., Kornblum, S.(Eds.), Attention and Performance XIV: Synergies in Experimental Psychology, Artificial Intelligence, and Cognitive Neurosciences. MIT Press, Cambridge, MA, pp. 611-653. 
Sanders, A.F., 1980. Stage analysis of reaction process. In: Stelmach, G.E., Requin, J. (Eds.), Tutorials in Motor Behavior. North-Holland, Amsterdam, pp. 331-354.

Sanders, A.F., 1990. Issues and trends in the debate on discrete vs continous processing of information. Acta Psychologica 74, 123-167.

Schulman, H.G., McConkie, A., 1973. S-R compatibility, response discriminability and response codes in CRT. Journal of Experimental Psychology 98, 375-378.

Smid, H.G.O.M., Mulder, G., Mulder, L.J.M., 1990. Selective response activation can begin before stimulus recognition is complete: A psychophysiological and error analysis of continous flow. Acta Psychologica 74, 169-201.

Sternberg, S., 1969. The discovery of processing stages: Extension of Donder's method. In: Koster, W.G. (Ed.). Attention and Performance II. Acta Psychologica 30, 276-315.

Stroud, J.M., 1955. The fine structure of psychological time. In: Quastler, H. (Ed.), Information Theory in Psychology. Free Press, New York.

Surwillo, W.W., 1963. The relation of simple response time to brain wave frequency and the effects of age. Electroencephalography and Clinical Neurophysiology 16, 510-514.

Titinen, H., Sinkkonen, J., Reinikainen, K., Alho, K., Lavikainen, J., Näätänen, R., 1993. Selective attention enhances the auditory $40 \mathrm{~Hz}$ transient response in humans. Nature 364, 59-60.

Treisman, M., Brogan, D., 1992. Time perception and the internal clock: Effects of visual flicker on the temporal oscillator. European Journal of Cognitive Psychology 4, 41-70.

Treisman, M., Cook, N., Naish, P.L.N., MacCrone, J.K., 1994. The internal clock: Electroencephalographic evidence for oscillatory processes underlying time perception. The Quarterly Journal of Experimental Psychology 47A (2), 241-289.

Treisman, M., Faulkner, A., Naish, P.L.N., Brogan, D., 1990. The internal clock: Evidence for a temporal oscillator underlying time perception with some estimates of its characteristics frequency. Perception 19, 705-743.

Treisman, M., Faulkner, A., Naish, P.L.N., 1992. On the relation between time perception and the timing of motor action: Evidence for a temporal oscillator controlling the timing of movement. Quarterly Journal of Experimental Psychology 45A, 235-263.

Wing, A.M., Kristofferson, A.B., 1973a. The timing of interresponse intervals. Perception and Psychophysics 13 (3), 455-460.

Wing, A.M., Kristofferson, A.B., 1973b. Response delays and the timing of discrete motor responses. Perception and Psychophysics 14 (1), 5-12. 